\title{
Philip Stewart, L'Invention du sentiment: roman et économie affective au XVIII siècle
}

\section{Regina Bochenek Franczakowa}

\section{(2) OpenEdition}

\section{Journals}

\section{Édition électronique}

URL : http://journals.openedition.org/studifrancesi/5937

DOI : 10.4000/studifrancesi.5937

ISSN : 2427-5856

\section{Éditeur}

Rosenberg \& Sellier

\section{Édition imprimée}

Date de publication : 1 mai 2011

Pagination : 166

ISSN : 0039-2944

\section{Référence électronique}

Regina Bochenek Franczakowa, «Philip Stewart, L'Invention du sentiment: roman et économie affective au xvIII siècle », Studi Francesi [En ligne], 163 (LV | I) | 2011, mis en ligne le 30 novembre 2015, consulté le 07 janvier 2021. URL : http://journals.openedition.org/studifrancesi/5937 ; DOI : https://doi.org/ ERREUR PDO dans /localdata/www-bin/Core/Core/Db/Db.class.php L.34 : SQLSTATE[HY000] [2006] MySQL server has gone away

Ce document a été généré automatiquement le 7 janvier 2021.

\section{$(1) \Theta \Theta$}

Studi Francesi è distribuita con Licenza Creative Commons Attribuzione - Non commerciale - Non opere derivate 4.0 Internazionale. 


\title{
Philip Stewart, L'Invention du sentiment: roman et économie affective au XVIII siècle
}

\author{
Regina Bochenek Franczakowa
}

\section{RÉFÉRENCE}

PHILIP STEWART, L'Invention du sentiment: roman et économie affective au XVIII siècle, Oxford, Voltaire Foundation, 2010 (SVEC 2010:02), pp. 250.

1 Le genre sentimental du XVIII ${ }^{\mathrm{e}}$ siècle a déjà été suffisamment exploré, surtout en ce qui concerne la deuxième moitié du siècle; l'auteur se propose d'examiner le phénomène à ses débuts, dans la période du matin des Lumières. Sans être sentimentale, «l'ère de Prévost et de Marivaux [...] est bien l'ère du sentiment», affirme à juste titre Philip Stewart (p.3). L'analyse porte donc sur la nouvelle manière de comprendre et d'exprimer le sentiment qui a peu à peu pénétré dans le roman français après 1700. L'A. établit d'abord les bases épistémologiques: il trace l'évolution que le mot «sentiment»a connue depuis le xVII siècle, examine le rapport entre le lexique et le sentiment prenant en considération les différences entre les cultures et les époques, rappelle les idées de Descartes et des écrivains de l'âge classique sur les passions, présente enfin les changements qui se sont opérés au tournant du siècle dans la philosophie ainsi que dans le goût du public, qui cherche des sentiments nouveaux dans l'art. La perspective de cette approche est délibérément fondée sur les acquis des théories psychologiques modernes, ce qui permet à l'A. de considérer les œuvres littéraires dans leur valeur cognitive, celle qui approfondit la connaissance du psychisme humain: le récit à la première personne s'y prête à merveille. L'analyse, menée avec une grande finesse et perspicacité, des romans de l'abbé Prévost, Marivaux et Claude Crébillon, fait ressortir ce qui distingue la façon dont ces auteurs représentent et expriment les sentiments: l'attrait de l'infortune chez le premier, l'art de la nuance chez le second, le désir de 
sincérité chez le dernier font partie des contrats de lecture différents; ce qui leur est commun, c'est «la réorientation du roman, et avec lui toute la sensibilité de la littérature française du XVIII ${ }^{\mathrm{e}}$ siècle» (p. 157).

2 L'A. s'intéresse aussi à l'évolution du mot «sentiment» tout au long du siècle: l'influence de Richardson, mais encore, de la comédie «larmoyante» dans les années 1730-40, jointe à la réflexion philosophique tendant à fusionner l'affect et la sensation en un tout, le «sentiment moral» - tout cela mène à une nouvelle manière de concevoir et de représenter les sentiments, à considérer en rapport avec «tout un mouvement qui voudrait trouver une moralité séculière qui soit sûre et, si possible, universelle» (p. 189). À la fin du volume, le lecteur trouvera en «Appendices» des "Éléments de vocabulaire: ébauche d'une étude du lexique affectif» (pp. 211-235), et deux "Tables» fort intéressantes et instructives: l'une comparative, qui inventorie la distribution des mots affectifs dans cinq romans (La Vie de Marianne, Le Philosophe anglais, Les Égarements du cœur et de l'esprit, Les Heureux Orphelins et La Nouvelle Héloïse) et l'autre qui présente le vocabulaire affectif dans un seul roman, $L a$ Vie de Marianne. Dans les réflexions qui introduisent ces inventaires, l'A. communique ses perplexités quant à la méthode: celle-ci est forcément limitée, car l'expression des sentiments "est souvent oblique» (214); elle permet néanmoins de rendre compte de l'histoire de l'expression affective. 